\title{
A experiência da gestão e planejamento do turismo das cidades patrimônio cultural da humanidade na Espanha aplicada à realidade brasileira
}

\section{The experience of tourism management and planning of the world heritage cities in Spain applied to the brazilian reality}

\author{
Kelly Lima Teixeira (TEIXEIRA, K. L.) ${ }^{*} \mathrm{e}$ \\ Marcos Leandro Silva Oliveira (OLIVEIRA, M. L. S.) ${ }^{* *}$
}

\begin{abstract}
RESUMO - As cidades brasileiras Patrimônio da Humanidade têm enfrentado diversos desafios no sentido de conciliar uma relação harmônica entre o patrimônio e o turismo. O propósito deste artigo é discutir a importância de uma maior articulação por parte das instituições públicas e privadas para a gestão compartilhada e responsável do turismo nestas localidades, tomando como referência o modelo de gestão turística das cidades patrimoniais espanholas. $\mathrm{O}$ trabalho foi desenvolvido com base na revisão bibliográfica. As considerações expostas não encerram a dimensão da temática; envereda-se pelo caminho de suscitar novas reflexões e dinâmicas que contribuam para o surgimento de novas formas de gestão turística em escala local e para o fortalecimento do associativismo entre estes destinos.
\end{abstract}

Palavras-chave: Cidades Patrimônio Cultural da Humanidade; Turismo Cultural; Gestão Turística; Planejamento Turístico.

\begin{abstract}
Brazilian Heritage cities have faced several challenges in order to reconcile a harmonious relationship between heritage and tourism. The purpose of this paper is to discuss the importance of greater interaction by the public and private institutions for co-management and responsible tourism, taking as reference the model of tourism management of Spanish heritage cities. The work was developed based on literature review. The considerations do not finish off the issue; they pursuit to raise new ideas and dynamics that contribute to new forms of tourism management at local level and to strengthen up association among these destinations.
\end{abstract}

Key words: Word Heritage Cities; Cultural Tourism; Tourism Management; Tourism Planning.

\footnotetext{
* Bacharel em Turismo pela Universidade Federal de Minas Gerais (UFMG). Especialista em Gestão Mercadológica em Turismo e Hotelaria pela Universidade de São Paulo (USP). Mestranda em Turismo pela Universidade de Santiago de Compostela (USC/Espanha). Endereço: Avenida Burgo das Nacións, s./n., Campus Norte. 15782 - Santiago de Compostela - A Coruña (Espanha). Telefone (00+ 34) 981563100 - ramal 11600. Email: Kelity@yahoo.com.br

** Licenciado em História pela Universidade do Sul de Santa Catarina (UNISUL). Doutorando em Geografia pela Universidade de Santiago de Compostela (USC/Espanha). Endereço: Instituto de Pesquisas Ambientais e Desenvolvimento Humano Catarinense (IPADHC). Rua Ouro Preto, 42 (Centro). CEP: 88745-000 - Capivari de Baixo - SC, Brasil. Telefone (48) 3623-3035. E-mail: marcosleandrok@yahoo.com.br
} 


\section{INTRODUÇÃO}

Verifica-se atualmente uma maior valorização do turismo cultural no Brasil incentivada pela tendência crescente do reconhecimento dos conjuntos urbanísticoarquitetônicos das chamadas cidades Patrimônio Cultural da Humanidade. O maior interesse pelos recursos culturais fomenta as visitas a estas cidades que se encontram cada vez mais associadas ao turismo.

As cidades históricas estão submersas em um contexto geral de crescimento da demanda turística relacionada com os bens culturais e patrimoniais. $\mathrm{O}$ turismo cultural vinculado com as cidades monumentais é, nos dias de hoje, um dos segmentos turísticos sujeitos à maior taxa de crescimento anual (HERNANDEZ, 2000).

De acordo com Vinuesa (1998), o turismo cultural está se convertendo em um protagonista fundamental da vida e também da recuperação urbana de diversas cidades históricas, ao induzir processos de recuperação e reutilização do patrimônio, bem como melhorias no espaço urbano e nas infra-estruturas e equipamentos culturais.

O desenvolvimento turístico pode contribuir para revitalizar a economia das cidades patrimoniais, dinamizando diversos setores, gerando renda e emprego e introduzindo novos produtos e serviços. O turismo favorece o desenvolvimento harmônico das cidades, promovendo o equilíbrio entre as necessidades locais e os projetos de crescimento econômico. Assim, a atividade turística permite que as cidades históricas dêem respostas às suas crises econômicas e funcionais, solucionando determinados desequilíbrios sociais (VINUESA, 1998). Para isto é necessário que estes destinos estejam bem administrados no âmbito turístico e urbanístico.

O turismo modifica de forma significativa a vida e a economia das cidades históricas, portanto, é fundamental administrar as suas múltiplas implicações, estabelecendo estratégias explícitas de compatibilidade com patrimônio cultural, meio ambiente, sociedade e economia. Deve-se ter em conta que o turismo não é uma atividade inofensiva e seu crescimento incontrolado pode levar à saturação urbanística e produzir efeitos negativos sobre os recursos patrimoniais, na qualidade de vida da população local e também sobre a experiência do visitante (VAQUERO, 2002). 
Neste contexto, as cidades históricas enfrentam um importante desafio: saber aproveitar as oportunidades que o turismo lhes oferece e conciliá-las com sua inserção equilibrada na política urbana, na economia e na sociedade.

Diante deste desafio, este trabalho se propõe identificar novos modelos de gestão para o turismo das cidades patrimoniais brasileiras que busquem promover uma maior articulação entre os agentes públicos e privados, além de um maior associativismo para que se tornem destinos mais competitivos e atraentes no cenário turístico nacional. Trata-se de propor estratégias de desenvolvimento turístico sustentável que contribuam para a geração de benefícios socioeconômicos nas cidades patrimoniais brasileiras, a exemplo do que vem ocorrendo no contexto espanhol.

Este trabalho foi desenvolvido com base na revisão bibliográfica sobre o tema, em especial na bibliografia de autores espanhóis que participaram ativamente da formação do Grupo de Cidades Patrimônio da Humanidade da Espanha (GCPHE), como Miguel Angel Troitiño Vinuesa, Maria García Hernandez e Maria de la Calle Vaquero. O presente artigo se baseia em um modelo de boas práticas, como é o caso do planejamento e gestão turística das cidades patrimoniais espanholas. A vantagem destes exemplos é propiciar um entendimento mais profundo de determinados processos, uma vez que permitem comparações entre diferentes realidades e a conseqüente adaptação dos modelos bem sucedidos, aplicados para outras localidades. No entanto, compreender as interações entre turismo e cidades patrimoniais requer uma visão inovadora que encare os desafios sociais, ambientais e funcionais gerados pela pressão e utilização turística do patrimônio e dos recursos culturais (HERNANDEZ, 2000).

Segundo Vinuesa (1998), a singularidade e fragilidade dos conjuntos monumentais, bem como a "multifuncionalidade" à qual se submetem as cidades Patrimônio da Humanidade exigem uma maior articulação por parte das instituições públicas e privadas para a gestão compartilhada e responsável do turismo nestas cidades. Neste sentido, busca-se demonstrar o esforço do Grupo de Cidades Patrimônio da Humanidade da Espanha para a organização e promoção turística conjunta. Este fato tem contribuído para o surgimento de novas formas de gestão turística em escala local e também tem fortalecido o associativismo entre estes destinos. Sem dúvida, as cidades históricas espanholas constituem um referencial básico da oferta e organização do turismo cultural e urbano. 
Em suma, o turismo adequadamente planejado e administrado pode auxiliar as cidades patrimoniais brasileiras a reforçar as suas "multifuncionalidades" e se beneficiarem de uma melhor vida urbana.

\section{PATRIMÔNIO, TURISMO E CIDADES HISTÓRICAS}

De acordo com o projeto Atlante (2005), as cidades históricas se constituem num dos destinos turísticos mais antigos, em consequiência da suas condições urbanas e dos seus recursos culturais. Segundo o manual Turismo Cultural: orientações básicas publicado pelo Ministério do Turismo (2006), a relação entre cidade, cultura e turismo é intrínseca e tem sua origem no grand tour europeu do século XVI, quando os aristocratas e mais tarde a burguesia viajavam principalmente para contemplar monumentos, ruínas e obras de arte dos antigos gregos e romanos.

Desde aquela época o patrimônio dos centros históricos se constitui num dos símbolos de identidade mais característicos, além de ser um dinamizador da vida cultural, social e urbana destes destinos. De acordo com Rodriguez (2001), o conceito de patrimônio refere-se ao legado histórico, arquitetônico e artístico que foi herdado do passado e que é transmitido às gerações futuras. Trata-se de um elemento simbólico de legitimação social e cultural de determinados objetos e tradições que conferem o sentimento coletivo de identidade a um determinado povo. Conforme os autores mencionados, a partir da década de 1970 verificou-se uma valorização do patrimônio cultural como fator de memória das sociedades.

Moraes (2002), afirma que o patrimônio cultural é a principal base para o desenvolvimento do turismo nas cidades históricas. O patrimônio tornou-se um componente essencial do turismo com implicações econômicas e sociais evidentes. Em contrapartida, o turismo promove a valorização dos recursos patrimoniais, considerando que o interesse do visitante pelos atributos singulares de um destino pode reforçar o sentimento de orgulho e de pertencimento. Este sentimento por sua vez, desperta na população local a valorização do patrimônio. Como apreciador, o sujeito começa a se identificar com aquele patrimônio enquanto elemento de identidade social, e neste sentido, o próprio indivíduo passa a ser o maior protetor deste patrimônio cultural (RODRIGUEZ, 2001). 
Seguindo os preceitos de Moraes (2002), o turismo cultural adquiriu um papel relevante nos processos decisórios relativos à preservação das cidades e de suas memórias culturais. Considera-se como turismo cultural aquelas viagens que têm como principal motivo o conhecimento dos recursos culturais e patrimoniais de outras localidades. Conforme a Carta de Turismo Cultural, publicada pelo Conselho Internacional de Monumentos e Sítios (ICOMOS) em 1976, o turismo cultural é: "aquela forma de turismo que tem por objetivo o conhecimento de monumentos e sítios histórico-artísticos. Exerce um efeito realmente positivo sobre estes contribuindo à sua manutenção e proteção".

Existem diversas definições para o turismo cultural, entre as quais se destaca a estabelecida pelo Ministério do Turismo do Brasil em parceria com o Ministério da Cultura e com o Instituto do Patrimônio Histórico Artístico Nacional - IPHAN: "Turismo Cultural compreende as atividades turísticas relacionadas à vivência do conjunto de elementos significativos do patrimônio histórico e cultural e dos eventos culturais, valorizando e promovendo os bens materiais e imateriais da cultura". (MINISTÉRIO DO TURISMO, 2006, p. 12).

Observa-se, desta forma, que o turismo cultural pode ser considerado um importante instrumento para a economia das cidades patrimoniais, contribuindo também para sua regeneração urbana, reabilitação arquitetônica e para a preservação do patrimônio e dos recursos culturais. Sendo assim, o turismo representa um pilar fundamental no desenvolvimento socioeconômico destes destinos (VICENTE; GUZMÁN, 2004).

No Brasil, o turismo cultural é freqüentemente associado às viagens para as cidades históricas ${ }^{1}$ que carregam consigo a imagem de um patrimônio cultural reconhecido, predominantemente, pelas edificações e monumentos arquitetônicos dos séculos XVI, XVII e XVIII, como é o caso de cidades como Salvador, Olinda, São Luís, Ouro Preto, Diamantina, Congonhas, entre outras. Nestas cidades, o turismo é considerado um dos principais agentes modificadores da ambiência urbana.

\footnotetext{
${ }^{1} \mathrm{O}$ termo "Cidades Históricas" tem sido comumente associado às cidades brasileiras de origem colonial. Neste artigo este termo é utilizado para designar tanto os núcleos urbanístico-arquitetônicos, como os centros históricos protegidos por lei no Brasil e em alguns países do mundo, tais como Ouro Preto, Salvador, Olinda, São Luís, Cidade de Goiás, São Miguel das Missões, Congonhas, Diamantina, dentre outras.
} 
Como cidade histórica, compreende-se a cidade herdada, surgida durante o período pré-industrial (colonial no caso brasileiro), que se configura como um produto histórico-social de caráter singular (ATLANTE, 2005). Tal tipo de cidade se caracteriza por sua "multifuncionalidade", realçada pelas suas dimensões sociais e funcionais de um núcleo urbano como outro qualquer. Por um lado, a cidade histórica se caracteriza pela heterogeneidade de seus moradores e visitantes. Por outro, trata-se de um espaço em que convivem diversas funções sejam elas de caráter administrativo, residencial, comercial ou turístico.

As cidades históricas brasileiras, designadas pelo título de Cidades Patrimônio Cultural da Humanidade, têm se esforçado para consagrarem-se como destinos de visita, fenômeno incentivado pela atual mudança da demanda turística que está em busca de novos produtos. A influência do turismo tem sido cada vez mais percebida como uma fonte de benefícios pelas administrações locais. Contudo, é importante ser consciente de que a afluência excessiva ou descontrolada de turistas pode provocar efeitos não desejados ou inclusive de incidir negativamente no patrimônio (ATLANTE, 2005).

Em muitos lugares o turismo se revelou prejudicial ao patrimônio cultural ou ineficaz como estratégia de promoção, quer pela falta de recursos humanos especializados, pela visitação descontrolada, pelo desrespeito em relação à identidade cultural local, pela imposição de novos padrões culturais, especialmente em pequenas comunidades, quer pelo despreparo do próprio turista para a experiência turística cultural (MINISTÉRIO DO TURISMO, 2006).

Neste contexto, vale ressaltar a importância do manifesto da cidade patrimonial de Santiago de Compostela ${ }^{2}$ na Espanha, a favor da cooperação ativa e da gestão sustentável das Cidades Patrimônio da Humanidade. Assim, para que as cidades patrimoniais possam encarar o desafio da sustentabilidade De acordo com Vinuesa (2002), o Manifesto de Santiago de Compostela reclama apoio e compromisso social para a conservação ativa do patrimônio, bem como uma implicação mais explícita do setor turístico. Assim, para que as cidades patrimoniais possam encarar o desafio da

\footnotetext{
2 Em Outubro de 1999, o V Colóquio Internacional das Cidades Patrimônio da Humanidade e a IV Assembléia da Organização das Cidades Patrimônio Mundial (OCPM) reuniram em Santiago de Compostela (Espanha) cerca de 70 prefeitos de cidades patrimoniais de 45 países, além de participantes da UNESCO, da Organização Mundial do Turismo (OMT) e da ICOMOS. As discussões promovidas nestes grandes eventos deram lugar ao documento denominado "Manifesto de Santiago de Compostela das Cidades Patrimônio da Humanidade" em favor da conservação ativa do patrimônio e da gestão sustentável destas cidades.
} 
sustentabilidade turística e urbana, torna-se especialmente necessário que os organismos administrativos adotem uma visão inovadora, dinâmica e integral (ATLANTE, 2005).

Frente a este cenário, evidencia-se a importância de promover ações conjuntas, planejadas e geridas entre as áreas de turismo e da cultura. Além disso, é fundamental preparar e proteger os patrimônios culturais para que se possa incorporá-los à atividade turística. Coube a Organização das Nações Unidas para a Educação, Ciência e Cultura (UNESCO) o papel de desenvolver ações de suporte e adoção de instrumentos internacionais para a proteção dos patrimônios mundiais, criando em 1978 a Lista do Patrimônio Mundial, na qual se destacam as Cidades Patrimônio Cultural da Humanidade. Um local denominado patrimônio da humanidade é reconhecido pela UNESCO como sendo de importância mundial para a preservação dos patrimônios históricos e naturais dos diversos países.

De acordo com a UNESCO (2010), a Lista do Patrimônio Mundial inclui 890 bens naturais e culturais. Deste total, 689 são bens culturais, 176 naturais, 25 mistos, distribuídos em 148 países diferentes. Entretanto, a maioria destes bens está localizada na Europa. Por isso, a UNESCO passou a fomentar a inscrição de novos bens à Lista do Patrimônio Mundial para promover o equilíbrio regional e alcançar assim, uma maior credibilidade.

A credibilidade da Lista do Patrimônio Mundial é resultado da apresentação periódica de informes dos países sobre o estado de conservação dos lugares e bens tombados, sobre as medidas adotadas para preservá-los e os esforços realizados para sensibilizar o público com respeito ao patrimônio cultural e natural.

Para Moraes (2002), a inscrição de bens e lugares na Lista do Patrimônio Mundial representa um grande instrumento de marketing, sendo utilizada por muitos países para a divulgação de sua imagem, ampliando as possibilidades de atração de um número cada vez maior de turistas.

\section{AS CIDADES PATRIMÔNIO CULTURAL DA HUMANIDADE NA ESPANHA}

Segundo a UNESCO (2010), a Espanha é o segundo país do mundo com maior número de bens declarados Patrimônio Cultural da Humanidade, ranking liderado pela Itália. São quarenta e um bens listados no total, dos quais trinta e seis deles representam 
recursos culturais, três parques naturais e dois espaços mistos. Do total de recursos culturais (36), entre monumentos, expressões artísticas, rotas, destacam-se os conjuntos urbanísticos e os núcleos históricos de quinze cidades. As cidades incluídas na Lista de Patrimônio Cultural da Humanidade são: Alcalá de Henares, Ávila, Cáceres, Córdoba, Cuenca, Eivissa, Mérida, Salamanca, Santiago de Compostela, Segóvia, San Cristóbal de la Laguna, Tarragona, Toledo, Úbeda e Baeza. Trata-se de cidades com um valioso patrimônio cultural que se realçam dentro do sistema urbano espanhol pelo valor histórico e cultural dos seus conjuntos urbanos.

Das quinze cidades patrimoniais espanholas, treze delas formam o Grupo das Cidades Patrimônio da Humanidade da Espanha - GCPHE (figura 1); uma associação sem fins lucrativos criada em 1993 para trabalhar na solução compartilhada de problemas de fatores diversos (urbanos, sociais, patrimoniais e culturais) que afetam estes destinos. O grupo foi constituído para atuar de forma conjunta na defesa do patrimônio histórico e cultural destas cidades, realizando projetos e propostas comuns e estabelecendo políticas de intercâmbios de experiências, com objetivo de enfrentar problemáticas semelhantes.

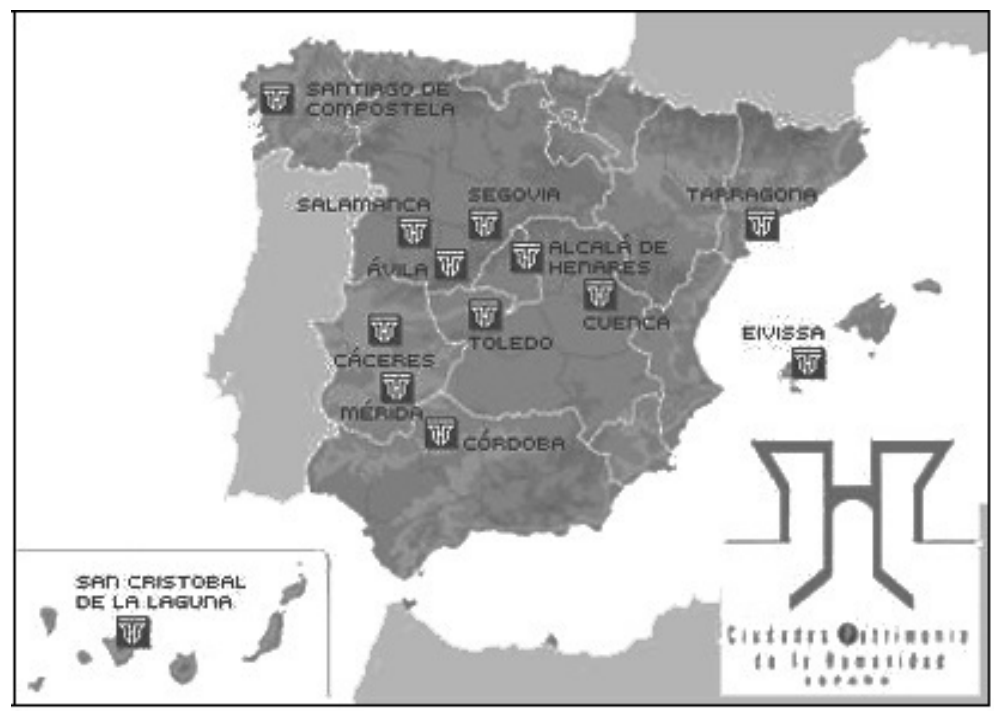

FIGURA 1- LOCALIZAÇÃO DAS CIDADES PATRIMÔNIO DA HUMANIDADE NA ESPANHA. FONTE: GRUPO DE CIUDADES PATRIMONIO DE LA HUMANIDAD DE ESPAÑA, 2007.

Desde 2004, o grupo formou o Clube de Produtos Cidades Patrimônio com o intuito de oferecer produtos padronizados, ou seja, foram desenvolvidos nestes destinos 
produtos turísticos semelhantes, que pudessem remeter à marca "Cidades Patrimônios da Humanidade".

Para Hernandez (2007), o repentino reconhecimento do valor histórico patrimonial e a grande promoção turística das cidades como Santiago de Compostela e Salamanca, contribuíram para que a atividade turística ocorresse de forma espontânea e aleatória, sem o acompanhamento necessário para o desenvolvimento sustentável da atividade. O grande volume de visitantes não foi respaldado com o desenvolvimento de políticas turísticas explícitas, nem por investimentos em infra-estrutura que pudessem sustentar a atividade.

Estas cidades já vinham recebendo um grande fluxo turístico desde a década de 60, mas, careciam de uma política turística estratégica. Na realidade, grande parte das cidades Patrimônio da Humanidade veio a constituir recentemente departamentos municipais responsáveis pelo planejamento e gestão turística. Tais destinos já recebiam milhares de visitantes sem realizar maiores esforços para captá-los.

Entretanto, na última década, o contexto turístico em que se inseriram estas Cidades Patrimônio Cultural da Humanidade, exigiu destes destinos novas estratégias para manter e ampliar suas participações no mercado turístico espanhol e mundial. O surgimento de destinos emergentes e a concorrência direta dos destinos de sol e praia estão obrigando estas cidades a diversificar a oferta turística básica e potencializar novos segmentos como o turismo de congressos, industrial e de compras. (HERNANDEZ, 2007). Além disso, as novas tendências turísticas e as alterações no comportamento e no perfil dos turistas têm fortalecido a necessidade de renovar e melhorar o produto turístico tradicional (oferta patrimonial).

Neste sentido, o desenvolvimento de políticas e programas de atuações turísticas requer uma maior inserção da administração local. O processo de transformação do modelo tradicional de gestão turística em uma gestão integrada promove um maior envolvimento da administração pública e da iniciativa privada, que muitas vezes assume o papel de órgão consultor.

O GCPHE tem trabalhado pelo reforço nas políticas turísticas em base local. O turismo adquire assim um papel de destaque dentro da política municipal e este "peso político" se manifesta em três linhas principais: 
- Adoção de novos modelos de planejamento baseados em conceitos de qualidade, sustentabilidade e colaboração público-privada;

- Ampliação das atuações em termos de gestão, ultrapassando as funções clássicas de promoção e regulação. Nestes momentos, fomentou-se a recuperação urbana, a melhoria da oferta patrimonial, a gestão da qualidade e a formação dos recursos humanos;

- Incentivo à criação e consolidação de entidades de gestão turística que, em alguns casos, se distinguem do modelo funcional das administrações públicas. Estas entidades têm com o objetivo planejar de forma mais flexível as políticas e planos para o desenvolvimento, promoção, gestão e dinamização dos municípios.

Desta forma, o cenário turístico das cidades patrimoniais espanholas se transforma com o aparecimento das novas entidades de gestão, tais como as Unidades de Gestão Pública do Turismo (departamentos e secretarias de turismo), Organismos Autônomos, Consórcios, Sociedades 100\% Públicas ou Mistas, Fundações e Associações. Estas entidades têm como papel-chave aumentar a eficiência das políticas públicas e dos programas usados para implantá-las. São instrumentos jurídicos próprios criados especificamente para realizar atividades de gestão turística, constituindo ferramentas fundamentais para o desenvolvimento sustentável das cidades patrimoniais.

De acordo com Hernandes (2007), as Cidades Patrimônio Cultural da Humanidade da Espanha têm despendido um esforço considerável durante os últimos anos para a melhoria dos aspectos necessários para aprimorar as suas competitividades turísticas. Com isso o turismo ganhou mais espaço nas pautas da discussão da política local e se constituiu em um pilar relevante para as economias das cidades históricas, tendo contribuído também para colocar em prática diversos programas de recuperação e preservação do patrimônio cultural, como ocorreu, por exemplo, nas cidades de Cuenca e Santiago de Compostela.

No entanto, um dos grandes desafios econômicos e sociais que as cidades patrimoniais terão que enfrentar nos próximos anos será o de se adequar aos novos perfis das demandas turísticas e culturais. Esta adequação funcional apresenta dificuldades de implantação na maior parte dos destinos que não preparou seus bens patrimoniais para um adequado uso turístico. 
Segundo Assis (2003, p. 47), muitas cidades históricas se encontram em uma encruzilhada, pois o patrimônio urbano passa a ser reivindicado como produto de consumo e se converte em um recurso turístico sem legitimidade que omite a verdadeira ambiência da cidade. A cidade histórica e turística, afastada do cotidiano, de seus usos e costumes, transforma-se, então, em um cenário estereotipado que estabelece uma continuidade artificial com o passado histórico.

Assim, os centros históricos evoluem em duas direções paralelas e dissociadas que refletem, de um lado, a cidade revelada ao turista, e de outro, a cidade real do cotidiano urbano que se caracteriza pela relação homem-ambiente.

Neste contexto, cabe destacar o papel que vem desempenhando o Grupo espanhol no sentido de combater a "banalização" e a "mercantilização" do patrimônio cultural. De acordo com o GCPHE (2009), seu trabalho busca implementar estratégias competitivas que permitam posicionar a Espanha como destino líder a partir do aproveitamento dos conjuntos patrimoniais para a criação de produtos turísticos, desenvolvimento econômico sustentável, geração de conhecimento e formulação de estratégias de gestão e cooperação. O propósito é consolidar as cidades deste grupo como destinos turísticos diversificados, alinhando os valores de solidez, sustentabilidade e estabilidade no desenvolvimento desta atividade socioeconômica.

Com o intuito de criar instrumentos de análise sobre a demanda, a oferta e os impactos do turismo nas cidades do GCPHE, foi criado em 2006 um sistema de informação turística através do qual é possível analisar periodicamente a evolução da atividade no conjunto dos destinos, construindo conhecimento sobre as peculiaridades e prioridades destas localidades.

Atualmente, a maior parte das Cidades Patrimônio da Humanidade na Espanha está vinculada ao Sistema Integral de Calidad Turística en Destino (SICTED). Verificase que seu nível de implantação varia consideravelmente nas treze cidades que compõem o grupo. No entanto, algumas cidades já contam com os distintivos de qualidade correspondente à certificação do sistema. Pode-se afirmar que a criação do SICTED seja um avanço na busca de aperfeiçoamento dos modelos de colaboração público-privada no âmbito de gestão turística, tema pendente no qual se encontram poucos casos exemplares. Supõe-se assim que o futuro turístico dos destinos 
patrimoniais espanhóis está cada vez mais unido ao quesito qualidade para o conhecimento, inovação, gestão e trabalho em rede.

\section{AS CIDADES PATRIMÔNIO CULTURAL DA HUMANIDADE NO BRASIL}

A Lista do Patrimônio Mundial da UNESCO figura como um instrumento de salvaguarda dos bens culturais e naturais, fazendo com que o reconhecimento de sua importância leve ao estabelecimento de uma relação de co-responsabilidade e ajuda mútua na preservação e conservação desses lugares.

Para que um recurso cultural ou natural possa se candidatar a Patrimônio Mundial, deve antes figurar na Lista Indicativa do Patrimônio Mundial. Conforme a UNESCO (2010), os lugares e bens indicados para a Lista do Patrimônio Mundial devem cumprir alguns requisitos estabelecidos como critérios de seleção, tais como:

. Representar uma obra prima do gênio criativo humano;

. Revelar um importante intercâmbio de valores e experiências consideráveis, num dado período de tempo ou em uma área do mundo culturalmente determinada, no âmbito da arquitetura ou tecnologia, artes monumentais, planejamento urbano ou desenho da paisagem;

. Constituir um único ou ao menos excepcional testemunho para uma tradição cultural de uma civilização ainda presente ou já extinta;

. Constituir um excepcional exemplo de um tipo de construção, conjunto arquitetônico ou tecnológico ou paisagem que ilustra significativamente um ou vários períodos significativos da história humana;

- Constituir um excepcional exemplo de assentamento humano ou ocupação territorial tradicional e representativo de uma ou várias culturas, sobretudo quando essas se apresentam vulneráveis a impactos de transformação irreversível;

. Estar direta ou materialmente associado a eventos ou tradições vivas, a idéias ou crenças, trabalhos artísticos e literários de excepcional significado universal; 
. Constituir exemplo eminentemente representativo dos grandes estágios da história da Terra, incluindo o testemunho da vida, de processos geológicos em curso no desenvolvimento das formas terrestres ou elementos geomórficos ou fisiográficos de grande significado;

Constituir excepcional exemplo representativo de processos ecológicos e biológicos em curso na evolução e no desenvolvimento dos ecossistemas e comunidades de plantas e animais terrestres, aquáticos, costeiros e marinhos;

- Representar fenômenos naturais ou áreas de excepcional beleza natural e importância estética;

. Conter os mais importantes e significativos habitats naturais para a conservação in situ da diversidade biológica, incluindo aqueles que contenham espécies ameaçadas que possuem excepcional valor universal do ponto de vista da ciência ou sua conservação.

Estes critérios são revisados periodicamente pelo Comitê do Patrimônio Mundial e constituem a base principal para o trabalho deste organismo. Se um bem tombado como Patrimônio da Humanidade deixa de atender aos critérios mencionados, corre o risco de ser retirado da mencionada Lista. Além disto, o bem será incluído na Lista do Patrimônio Mundial em Perigo no caso em que se constatem riscos para a sua preservação.

O Brasil conta com 17 bens (figura 2) listados: 7 naturais e 10 culturais. Com relação aos bens culturais, sete deles compreendem núcleos históricos ou monumentos do período colonial, outros dois se destacam pelas pinturas rupestres e pelas ruínas jesuíticas, sendo que apenas Brasília figura como representante da arquitetura e do urbanismo moderno. Os processos de solicitação de inclusão dos bens brasileiros na Lista do Patrimônio Mundial remontam a meados da década de 80, quando Ouro Preto foi declarada a primeira cidade brasileira Patrimônio da Humanidade. 


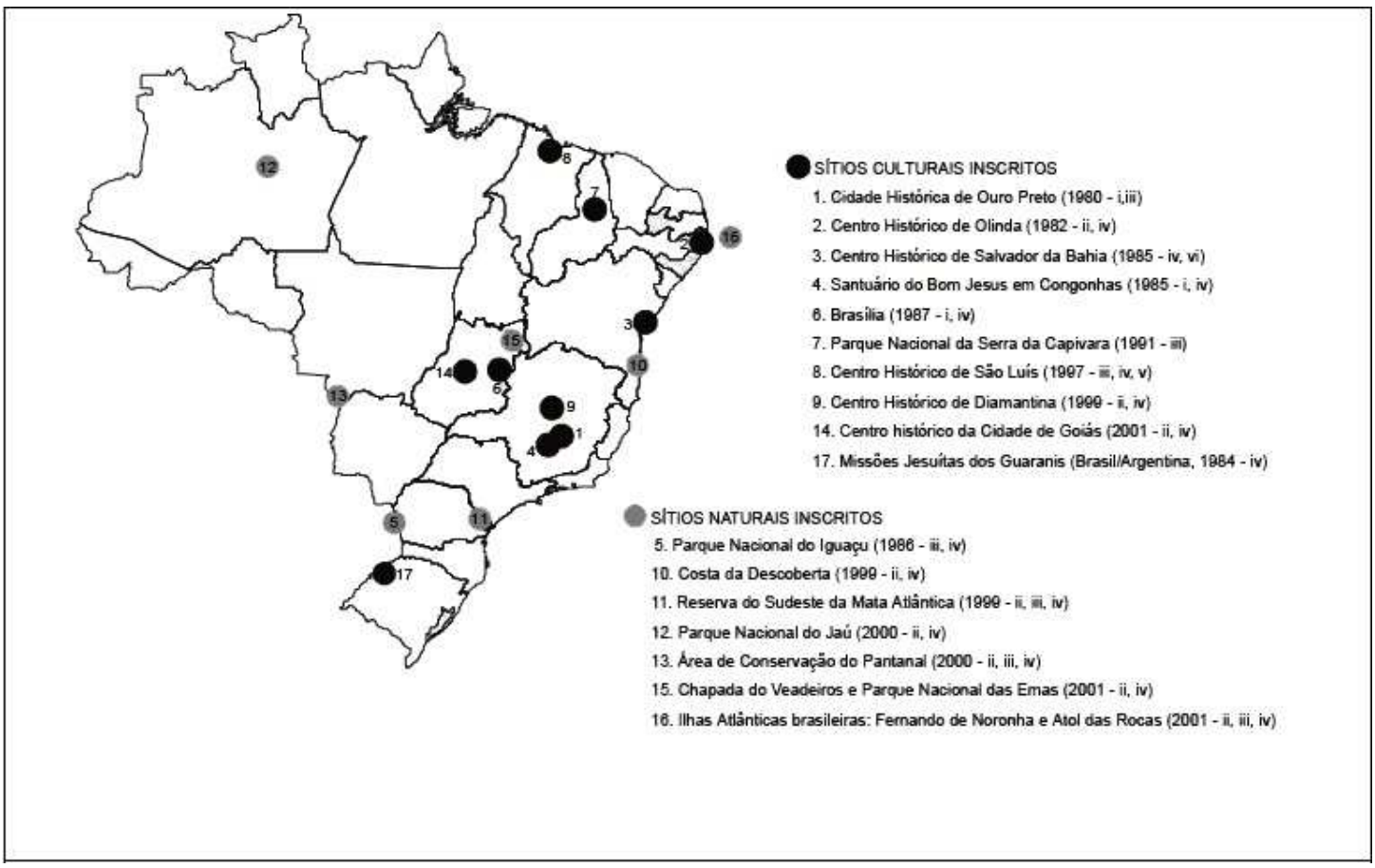

FIGURA 2- BENS BRASILEIROS INSERIDOS NA LISTA DE PATRIMÔNIO DA HUMANIDADE DA UNESCO.

FONTE: UNESCO. WORLD HERITAGE CENTRE, 2001.

Segundo o Ministério do Turismo (2006), o patrimônio e a pluralidade da cultura brasileira têm sido cada vez mais aclamados como recursos de grande significância para a atividade turística, que, por sua vez, representa uma possibilidade para o desenvolvimento das cidades históricas. O mérito desta possibilidade é fazer do turismo uma atividade capaz de promover e preservar a cultura brasileira.

Contudo, o potencial brasileiro para o turismo cultural não é devidamente aproveitado, já que boa parte dos produtos turísticos ofertados pelos destinos patrimoniais carece de qualificação e diversificação, necessitando diversos ajustes para chegar à competitividade e à sustentabilidade.

Além disto, em algumas cidades patrimoniais brasileiras a relação turismopatrimônio ocorre de forma conflituosa como consequiência da exploração turística inadequada deste patrimônio. Observa-se que em determinadas cidades patrimoniais brasileiras, a alta afluência de visitantes começa a gerar problemas de saturação turística concentrados espacialmente e temporalmente. Nestas localidades, o patrimônio cultural é incorporado nas atividades turísticas como uma espécie de "tábua de salvação". Segundo Moraes (2002, p. 4) o turismo não deve ser acometido como uma solução, pois ele também provoca transformações no espaço, na cultura local, nas práticas sociais 
cotidianas, gerando assim, impactos indesejáveis no cotidiano dos moradores. Como exemplo, pode-se mencionar os processos de expulsão de moradores residentes em centros históricos tal como ocorreu na cidade de Recife e no Pelourinho em Salvador. Em muitos casos, a população residente de centros históricos foi pressionada a vender seus imóveis em decorrência da especulação imobiliária gerada pelo turismo. Logo, a atividade pode desvincular, tanto espacialmente quanto socialmente, o patrimônio da comunidade à qual pertence. Por isso, o desafio que se coloca ao turismo é o de utilizar os recursos patrimoniais numa perspectiva de desenvolvimento sustentável, assentada em critérios de qualidade, para que os seus benefícios resultem numa efetiva melhoria da qualidade de vida dos cidadãos, tanto daqueles que o praticam como daqueles que o acolhem.

Esse cenário sinaliza a necessidade de implantar ações conjuntas, planejadas e geridas entre as áreas de turismo, urbanismo e cultura, para garantir a preservação dos bens e a vitalidade das cidades patrimoniais. As ações integradas devem abranger medidas de qualificação e revitalização que visem dotar um núcleo histórico ou um conjunto urbanístico de melhor infra-estrutura, para revigorá-lo e otimizar seu uso - isto é - re-significar o patrimônio.

Assim, é fundamental estabelecer uma harmonia mútua entre patrimônio e turismo a partir do planejamento que inclua a participação de entidades do poder local, iniciativa privada e comunidade. A gestão compartilhada favorece a conservação e valorização do legado cultural das gerações futuras, além de consagrar a identidade e o desenvolvimento turístico sustentável das cidades patrimoniais.

\section{PERSPECTIVAS PARA O TURISMO NAS CIDADES PATRIMÔNIO CULTURAL DA HUMANIDADE NO BRASIL}

É chegado o momento em que a simbiose entre turismo, diversidade cultural e desenvolvimento sustentável, ganha força no contexto mundial. A idéia parte do princípio de que a diversidade cultural constitui a base da sobrevivência do turismo e sua conservação e valorização corresponde à garantia para o desenvolvimento turístico respeitoso com as localidades nas quais se insere. Para compreender a dinâmica da 
utilização turística do patrimônio cultural torna-se necessário possuir uma visão inovadora que leve em conta os desafios culturais, econômicos, ambientais e funcionais do uso responsável do patrimônio frente à pressão da atividade turística. É oportuno enfatizar que o patrimônio cultural, em suas diversas manifestações, tem inúmeras possibilidades de utilização turística, todavia, isto requer um planejamento e gestão turística alinhados às singularidades de cada localidade.

O caso das cidades Patrimônio Cultural da Humanidade da Espanha demonstra que estas vêm realizando durante os últimos anos esforços importantes na adequação dos seus patrimônios culturais e têm reforçado as ações turísticas, fazendo com que o turismo ganhe espaço nas agendas políticas locais. É certo que estes resultados são consequiências de um trabalho intenso que tais cidades vêm realizando em termos de promoção e comercialização, fato que lhes conferiu maior visibilidade turística no cenário espanhol. Neste cenário, os dirigentes destas cidades se deram conta de que promoção e comercialização requerem planejamento contínuo, definição de estratégias, cooperação e principalmente gestão.

Desde a década de 90, as cidades monumentais espanholas já contavam com instrumentos de planejamento turístico como os Planos de Competitividade e Dinamização dos Destinos Turísticos Espanhóis. Atualmente, estes planos deram lugar aos planos de Excelência Turística que são parte importante no processo de reformulação do modelo de intervenção turística. Além disto, o associativismo contribuiu para que boa parte das Cidades Patrimônio da Humanidade superasse a visão tradicional da ação pública, que se limitava a promoção, apostando por uma intervenção mais ambiciosa no condicionamento integral das cidades como destino turístico.

Como resultado destas transformações, identificou-se linhas de frente para aumentar a competitividade dos centros históricos a partir da renovação da oferta turística tradicional, da diversificação de produtos turísticos e da criação dos observatórios turísticos. Estes últimos se encarregam da análise da demanda, oferta e dos impactos da atividade turística, para gerar dados que possam sustentar a tomada de decisões estratégicas e as políticas turísticas.

O despertar das Cidades Patrimônio Cultural da Humanidade da Espanha para o setor turístico, se refletiu em vários âmbitos relacionados com a planificação e gestão turística. Em primeiro lugar, na adoção de novas formas de planejamento sustentadas 
em pilares de qualidade, sustentabilidade e colaboração público-privada. Depois, pela ampliação e diversificação das atuações desenvolvidas pelo poder público local que passou a desempenhar muito mais que a promoção, se encarregando também pela melhoria da oferta patrimonial, da gestão da qualidade e da formação dos recursos humanos. E por último, na criação e consolidação de estruturas de gestão turística (consórcios, empresas públicas, observatórios turísticos, entre outros) adaptados às novas necessidades que se diferem do modelo de funcionalismo público tradicional. A criação destes organismos permite gerir e planejar de forma mais flexível a atividade turística nestas localidades.

O que se espera extrair do modelo espanhol e adaptar à realidade das cidades brasileiras Patrimônio da Humanidade é justamente o despertar da inércia que as fazem espectadoras e não espetáculo turístico.

A utilização do modelo espanhol como referencial, não significa a simples imitação deste modelo, até porque não existe modelo único a ser seguido por todos os destinos e, além disto, é importante respeitar as conjunturas socioculturais, históricas, políticas e econômicas que são bastante diversas. Na realidade, considera-se o modelo espanhol como um espelho que deve ser interpretado e a partir daí levar à construção de uma imagem própria capaz de potencializar a utilização adequada dos recursos que são singulares de cada lugar.

Muitas das cidades brasileiras declaradas Patrimônio Cultural da Humanidade têm seu turismo arraigado à exploração dos recursos urbano-arquitetônicos, como são os casos de Ouro Preto, Diamantina, Salvador, Olinda, Brasília, Congonhas, São Luís e Cidade de Goiás. A atração turística destas cidades depende fundamentalmente, embora não exclusivamente, das características do ambiente construído, da arquitetura e das formas urbanas.

Assim sendo, a conversão do patrimônio em produto turístico comercializado tem levado a exploração inadequada deste atributo e tem contribuído para ameaças enquanto sua preservação, a exemplo da cidade de Ouro Preto, que já correu o risco de ingressar na Lista de Patrimônio Mundial em Perigo ${ }^{3}$. Portanto, há que ter claro que a

\footnotetext{
${ }^{3}$ Em agosto de 2002, um representante do Instituto Patrimônio Histórico Artístico Nacional (IPHAN) de Ouro Preto participou em Olinda do "Evento das Cidades Patrimônio Histórico" promovido pela Caixa Econômica Federal e pela UNESCO realizado para avaliar as condições de preservação dos sítios históricos brasileiros declarados patrimônio da humanidade. Como resultado de sua participação, obteve
} 
cultura, o passado e o patrimônio não são objetos passíveis de compra e de venda. Quando isto ocorre, ao invés de se configurar como instrumento de conservação ambiental e de criação de benefícios socioeconômicos para as comunidades receptoras, o turismo, acaba em geral, por aumentar o processo de degradação ambiental, gerando desequilíbrios socioeconômicos e desvalorização cultural.

Seguindo o cenário espanhol, a diversificação da oferta turística representa uma alternativa relevante para estas localidades. A promoção de novos segmentos como o turismo religioso, de reuniões e eventos, de negócios, industrial, entre outros; melhora a infra-estrutura local, envolve um maior número de pessoas nesta atividade e contribui para a geração de empregos.

Os destinos histórico-culturais do Brasil enfrentam o desafio de aproveitar as oportunidades que o turismo lhes brinda e explorar de forma responsável seus recursos, contribuindo para construir novos modelos de desenvolvimento. Para tanto é imprescindível que a atuação pública fomente o cooperativismo público-privadopopular com o intuito de superar as disparidades de interesses e de visões acerca do desenvolvimento turístico por parte todos agentes implicados. É necessário unir esforços para que a cooperação supere a mera colaboração, ou seja, é importante fazer com que todos os agentes compartam riscos e benefícios que a atividade possa vir a gerar. Este modelo representa um instrumento fundamental para as políticas de preservação e salvaguarda do patrimônio cultural.

Diante deste cenário, o associativismo desponta como ferramenta de grande utilidade. O exemplo do GCPHE demonstra que a formação da rede de cidades patrimoniais que possuem características comuns, permite o apoio mútuo na defesa do patrimônio histórico e cultural, estabelecendo intercâmbios de experiências exitosas e enfrentando problemáticas comuns. Agindo desta forma, as cidades evitam repetições de erros e enfoques convencionais já vividos por outras localidades. A formação do GCPHE fomenta estudos sobre o fenômeno turístico nas cidades históricas, que contribuem para formular estratégias e propostas comuns que servem para amparar a utilização turística do patrimônio cultural.

uma moção pedindo medidas urgentes para a preservação de Ouro Preto. Do ponto de vista do patrimônio histórico, a cidade foi considerada mal-conservada, já que alguns dos seus bens patrimoniais foram danificados pela ação do tempo (sem respaldo de um processo de conservação) ou por acidentes como desabamentos e colisões. 
Em consonância aos estudos turísticos, a idéia espanhola de criação de observatórios turísticos parece muito válida, já que a análise da demanda, da oferta e do impacto turístico nestas localidades gera informações fundamentais para a tomada de decisões, para a gestão e para o planejamento do turismo. A produção de dados estatísticos e o conhecimento mais profundo sobre as características destes destinos permitem conhecer melhor as fortalezas, as debilidades, as ameaças e as potencialidades das cidades patrimoniais. Além disso, tais informações ajudam a identificar o perfil dos turistas, permitindo readaptar a oferta em função dos interesses de seus visitantes e contribui para a formação de uma imagem mais valorizada, assim como melhorar o posicionamento destas cidades no mercado turístico.

Em comparação com as cidades espanholas, existe um amplo caminho que as cidades brasileiras Patrimônio Cultural da Humanidade devem percorrer para estabelecer uma relação harmoniosa entre turismo e patrimônio. A fragilidade dos centos históricos e sua complexidade funcional explicam a dificuldade de implantar uma gestão que supere a dissociação entre administração turística, cultural e urbanística. O sucesso do desenvolvimento turístico de uma cidade patrimonial depende tanto da coordenação de políticas setoriais de implicação urbana (cultural, trânsito, segurança, urbanismo etc.) como da formulação explícita de políticas turísticas.

\section{CONSIDERAÇÕES FINAIS: UMA GESTÃO INOVADORA PARA RECURSOS SINGULARES}

Para interpretar e enfrentar a complexa problemática das cidades patrimoniais é necessário ter uma visão inovadora, dinâmica e integradora que encare os desafios culturais, econômicos, ambientais e funcionais que o uso responsável do patrimônio cultural e a pressão do turismo suscitam. Este fato reforça a necessidade de fomentar novos produtos e infra-estruturas relacionadas com a demanda turística. Possuir bens patrimoniais e fazer promoção já não são suficientes para que estas cidades se convertam em destinos turísticos de qualidade e com capacidade competitiva. É preciso recorrer ao planejamento e à gestão destes recursos para uso turístico. 
Nas cidades históricas, o planejamento turístico, urbanístico e do patrimônio cultural não podem ser ignorados. Estes três instrumentos representam os pilares básicos para alcançar uma recuperação urbana integrada e o desenvolvimento sustentável do turismo. Mesmo assim, é preciso que as administrações locais tenham em vista medidas para estabelecer vínculos mais estreitos entre as políticas de recuperação dos conjuntos históricos e as novas funcionalidades, visando: melhorar a cidade para os cidadãos; superar as interpretações monumentalistas do patrimônio cultural-arquitetônico e apostar por uma interpretação mais urbanística; definir políticas ativas de conservação do patrimônio cultural; preservar a imagem e as paisagens que configuram as cidades como destinos turísticos; incentivar a comercialização e diferenciação dos produtos turísticos. Em essência, as linhas de atuação devem se orientar para dar respostas operativas aos problemas das cidades históricas, aportando melhorias na paisagem urbana e nos equipamentos culturais. Entretanto, cabe ressaltar que uma verdadeira estratégia turística só se torna possível com a colaboração público-privada e a participação popular.

Os gestores das Cidades Patrimônio da Humanidade seguem gradativamente na busca de modelos de gestão mais sustentáveis. O caso das cidades patrimoniais espanholas representa um bom exemplo de adoção de medidas estratégicas para o desenvolvimento turístico sustentável. Entre estas medidas se destacam a criação do Grupo de Cidades Patrimônio da Humanidade de Espanha que atua de forma conjunta na defesa dos interesses comuns e da promoção turística das cidades membros, bem como a criação de organismos próprios encarregados das tarefas de planificação e gestão turística que supõe a consolidação do processo de desenvolvimento responsável destes destinos, melhorando suas competitividades no âmbito turístico. As cidades patrimoniais espanholas se tornaram conscientes da necessidade de articular mecanismos de colaboração, fato que lhes permitiu encarar de maneira conjunta, diversos desafios relacionados com a conservação, gestão e difusão do seu patrimônio.

No Brasil, os dirigentes das cidades Patrimônio Cultural da Humanidade necessitam introduzir mudanças constantes nos atuais modelos de gestão turística. É preciso se antecipar às alterações brutais no tecido urbano, evitando a banalização do patrimônio cultural e a perda de vitalidade dos núcleos históricos. 
A interpretação inovadora das relações entre patrimônio cultural, cidades históricas, urbanismo e turismo, exige a adoção de um sistema integrado de gestão que esteja amparado em estratégias sustentáveis, que possam potencializar o desdobramento do turismo para benefícios sociais e econômicos. Uma análise criteriosa do exemplo espanhol permitirá comparar realidades distintas, mas com experiências semelhantes; dentre as quais, as mais significativas podem ser interpretadas e adaptadas ao contexto brasileiro.

O turismo é um protagonista especial no cenário das cidades históricas, o qual enfrenta diversas dificuldades para consolidar-se como um instrumento de dinamização urbana, patrimonial e funcional destes destinos. Neste sentido, defende-se a necessidade de preparar e conservar as comunidades locais, para que tenham a preocupação com o uso correto de suas potencialidades turísticas, não permitindo que suas raízes e identidades culturais se percam no espaço e no tempo, mantendo assim de forma sustentável o patrimônio cultural. Como foco para outras pesquisas vindouras e correlatas pode-se mencionar a necessidade de inventariar situações de sucesso das cidades brasileiras e verificar as suas aplicabilidades em outros destinos do Brasil ou da Espanha.

\section{REFERÊNCIAS}

ASSIS, A. P. Conservação do Patrimônio e Turismo: arranjos e conflitos entre memória, história e consumo. 142 f. Dissertação (Mestrado em Arquitetura e Urbanismo) - Escola de Arquitetura da UFMG, Belo Horizonte, 2003.

ATLANTE. Desarrollo Turístico Sostenible en Ciudades Históricas. Proyecto mejorar las ciudades Atlánticas Patrimonio Mundial de la UNESCO. Ayuntamiento de Santiago de Compostela y Lugo, 2005.

GRUPO DE CIUDADES PATRIMONIO DE LA HUMANIDAD DE ESPAÑA. La Situación Turística del Grupo de Ciudades Patrimonio de la Humanidad de España: bases para la puesta en marcha del observatório turístico. Madrid: Universidad Complutense de Madrid, 2007.

Disponível em: < http://www.ciudadespatrimonio.org/index.aspx?lang=es-ES > Acesso em: 29/03/09. 
HERNANDEZ, M. G. Turismo y médio ambiente em ciudades históricas: la capacidad de acogida turística y la gestión de los flujos de visitantes. Anales de Geografía de La Universidad Complutense, Madrid, v. 20, n. 20 p. 131-148, 2000.

Entidades de Planificación y Gestión Turística a Escala Local. El Caso de las Ciudades Patrimonio de la Humanidad de España. Cuadernos de Turismo, Múrcia, n. 20, p. 79-102, 2007.

ICOMOS: Carta Internacional sobre Turismo Cultural. Paris: ICOMOS, 1976.

MINISTÉRIO DO TURISMO. BRASIL. Turismo cultural - orientações básicas. Brasília: Ministério do Turismo, 2006.

MORAES, F. B. Patrimônio Mundial: aspectos de uma política internacional para preservação de sítios naturais e culturais. Aqui - Arquitetura \& Cultura, Belo Horizonte, v. 1, n. 3, p. 62-70, 2002.

RODRIGUEZ, M. Preservar e consumir: o patrimônio histórico e o turismo. In: FUNARI, P.; PINSKY, J. (Orgs.). Turismo e Patrimônio Cultural. São Paulo: Contexto, 2001.

UNESCO. World Heritage Centre: Brief descriptions of sites inscribed on the World Heritage List. Paris: UNESCO, jan. 1999 (atualização em dez. 2001). $\begin{array}{cccc}\text { Whttp://whc.unesco.org/en/statesparties/br/>. } & \text { Acesso em: } & \text { Her/03/2010. } & \text { Disponível }\end{array}$

VAQUERO, M. La ciudad histórica como destino turístico. Barcelona: Ariel, 2002.

VICENTE, F.; GUZMÁN, T. El turismo como motor de desarrollo económico en Ciudades Patrimonio de la Humanidad. Pasos, Revista de Turismo y Patrimonio Cultural, v. 2, n. 2, p. 243-256, 2004.

VINUESA, M. A. Turismo y desarrollo sostenible en ciudades históricas. Ería Revista Cuatrimestral de Geografía. Oviedo: Departamento de Geografía de la Universidad de Oviedo, n. 47, p. 211-228, 1998.

Ciudades Patrimonio de la Humanidad: desafíos de interpretación, planificación y gestión turística. In: BLANQUER, D. Ordenación y Gestión del territorio turístico. Castellon: Tirant lo Blanch, 2002.

Recebido em: 30/11/2009

Aprovado em: 30/12/2009. 